\title{
Receptor for AGEs (RAGE) blockade may exert its renoprotective effects in patients with diabetic nephropathy via induction of the angiotensin II type 2 (AT2) receptor
}

\author{
K. C. Sourris • A. L. Morley • A. Koitka • P. Samuel • M. T. Coughlan • S. A. Penfold • \\ M. C. Thomas • A. Bierhaus • P. P. Nawroth • H. Yamamoto • T. J. Allen • T. Walther • \\ T. Hussain • M. E. Cooper • J. M. Forbes
}

Received: 18 March 2010 / Accepted: 20 May 2010 / Published online: 15 July 2010

(C) Springer-Verlag 2010

\begin{abstract}
Aims/hypothesis The receptor for AGEs (RAGE) contributes to the development and progression of diabetic nephropathy. In this study, we examined whether the protective effects of RAGE blockade are exerted via modulation of the renal angiotensin II type 2 (AT2) receptor.

Methods Control and streptozotocin diabetic mice, wildtype or deficient in the AT2 receptor (At2 knockout [KO]) or RAGE (Rage KO), were studied for 24 weeks. Adenoviral overexpression of full-length Rage in primary rat mesangial cells was also used to determine the effects on AT2 production.
\end{abstract}

K. C. Sourris and A. L. Morley contributed equally to this work.

Electronic supplementary material The online version of this article (doi:10.1007/s00125-010-1837-2) contains supplementary material, which is available to authorised users.

K. C. Sourris $(\varangle) \cdot$ A. L. Morley $\cdot$ A. Koitka $\cdot$ M. T. Coughlan •

S. A. Penfold • M. C. Thomas · T. J. Allen • M. E. Cooper •

J. M. Forbes

JDRF Einstein Centre for Diabetes Complications,

Baker Heart Research Institute,

PO Box 6492, St Kilda Rd Central,

Melbourne, Victoria 8008, Australia

e-mail: Karly.Sourris@bakeridi.edu.au

P. Samuel · T. Hussain

Heart and Kidney Institute, College of Pharmacy,

University of Houston,

Houston, TX, USA

\author{
A. Bierhaus $\cdot$ P. P. Nawroth \\ Department of Medicine I, University of Heidelberg, \\ Heidelberg, Germany
}

Results With diabetes, Rage-deficient mice had less albuminuria, and an attenuation of hyperfiltration and glomerulosclerosis as compared with diabetic wild-type and At2 KO mice. Renal gene and protein expression of RAGE was elevated with diabetes. Diabetic Rage KO mice had a greater increase in renal AT2 receptor protein than was seen in diabetic wild-type mice. Diabetes-induced increases in renal cytosolic and mitochondrial superoxide generation were prevented in diabetic Rage $\mathrm{KO}$ mice, but enhanced in all At $2 \mathrm{KO}$ mice. Adenoviral overexpression of RAGE or AGE treatment decreased cell surface AT2 expression, in association with increasing superoxide generation; both were

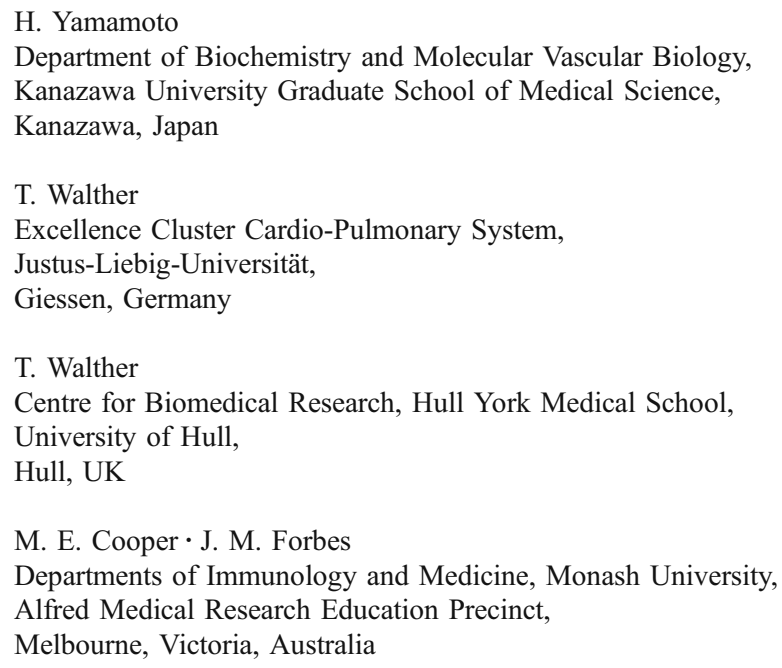


reversed using antioxidants $\mathrm{N}$-acetylcysteine and apocynin, and soluble RAGE in primary mesangial cells.

Conclusions/interpretation RAGE appears to be a common and key modulator of AT2 receptor expression, a finding that would implicate a newly defined RAGE-AT2 axis in the development and progression of diabetic nephropathy.

Keywords Advanced glycation - Angiotensin . AT1 receptor. AT2 receptor . Chronic kidney disease . Nephropathy

\begin{tabular}{ll}
\multicolumn{2}{l}{ Abbreviations } \\
AdGO & Empty vector control \\
AT1 & Angiotensin II type 1 \\
AT2 & Angiotensin II type 2 \\
KO & Knockout \\
NAC & $N$-Acetylcysteine \\
RAGE & Receptor for AGEs \\
RAS & Renin-angiotensin system \\
ROS & Reactive oxygen species
\end{tabular}

\section{Introduction}

The renin-angiotensin system (RAS) is a co-ordinated hormonal cascade, in which the protein angiotensin II elicits its effects by binding to cellular receptors, including the angiotensin II type 1 (AT1) and angiotensin II type 2 (AT2) receptors [1-3]. It is thought that AT1 and AT2 receptors elicit opposing actions upon ligand interaction with angiotensin II, whereby ligation to AT1 is thought to promote vasoconstriction, cellular growth, proliferation and fibrosis. By contrast, the AT2 receptor is thought to induce vasodilatation and natriuresis [4-7]. While the systemic RAS is dampened with diabetes, there is evidence that the renal RAS is activated [8,9]. Not surprisingly, angiotensin II and its receptors play a major role in the pathogenesis and progression of diabetic complications including nephropathy. The most widely used therapies for these disorders are inhibitors of angiotensin converting enzyme-1 [10, 11] and AT1 receptor ligation (AT1 antagonists) [12, 13] or a combination of both [14]. Although effective, these compounds do not completely abrogate renal disease, with progression to end-stage still occurring, albeit at a slower rate. Given that more clinically desirable, earlier intervention with these compounds does not confer additional renoprotection $[15,16]$, the discovery of additional synergistic pathways as potential drug targets is of paramount importance for diabetic complications.

There is strong experimental evidence supporting a pathogenic role for the receptor for AGEs (RAGE) in diabetic renal disease [17]. Indeed, Rage knockout (KO) mice have less renal injury with diabetes [18, 19]. Conversely, mouse models of diabetes genetically manipulated to overexpress Rage have significant glomerulosclerosis $[20,21]$. Our group, along with others, has demonstrated important interactions between the RAS and advanced glycation in diabetic nephropathy, first recognised by the finding that ACE inhibitors [22, 23] and AT1 antagonists [23-25] are potent inhibitors of AGE accumulation. We have also shown that administration of AGEs to rodents results in activation of the renal RAS in a manner similar to that seen with diabetes [26]. Moreover, we have also demonstrated that the beneficial effects of ACE inhibitors on nephropathy may involve modulation of soluble RAGE levels in experimental models and in type 1 diabetic patients [22]. In addition, angiotensin II upregulates RAGE production in podocytes, a mechanism that was postulated to occur via the AT2 receptor [27]. Since it is likely that the most rational approach to treatment of diabetic complications is combination therapies, studies have also demonstrated that blockade of the RAS and of AGE accumulation may have some synergistic effects [24, 28].

Currently, compounds targeting advanced glycation by decreasing AGE formation or via RAGE antagonism are under active investigation for the treatment of diabetic nephropathy. Hence, to assist in the design of more rational combination therapies that would target the RAS and AGEs in the treatment of diabetic nephropathy, we examined the effects on the AT2 receptor of manipulating RAGE production; this receptor is not currently targeted by ACE inhibition and AT1 receptor blockade.

\section{Methods}

Animals Mice deficient in the AT2 receptor (At2 KO) [29] or RAGE (Rage KO) $[30,31]$ were backcrossed on to the C57BL/6J background (wild-type for nine generations) and maintained at the Alfred Medical Research and Education Precinct Animal Services, Melbourne, Australia. The protocols followed for animal handling and experimentation were in accordance with ethical guidelines of the organisation's Animal Ethics Committee and the National Health and Medical Research Council of Australia.

Experimental model of diabetes Groups of 6-week-old ( $\mathrm{n}=$ 8-10 per group) male $\mathrm{KO}$ and wild-type mice (from colonies maintained within Baker IDI) were randomised to have diabetes induced via intraperitoneal injection with streptozotocin $\left(50 \mathrm{mg} \mathrm{kg}^{-1} \mathrm{day}^{-1}\right.$; MP Biomedicals, Eschwege, Germany) or to be sham-injected with vehicle (sodium citrate buffer, $\mathrm{pH} 4.5$ ) for 5 consecutive days as previously described [32] and in accordance with the 
Low-Dose Streptozotocin Induction Protocol (mouse) of the Animal Models of Diabetic Complications Consortium (AMDCC; www.amdcc.org/shared/protocols.aspx, accessed 1 June 2010). On the sixth day, blood glucose was tested using test strips (Accu-Chek Advantage II; Roche Diagnostics, Mannheim, Germany). Only mice with a blood glucose reading of $>15 \mathrm{mmol} / \mathrm{l}$ were included ( $>90 \%$ mice injected) in the diabetic groups of the study. Insulin was not administered as it was not required. Throughout the duration of the study, mice had free access to standard mouse chow and water. After 24 weeks mice were anaesthetised with pentobarbitone (10 mg/kg; Delvet Group, Seven Hills, NSW, Australia) and bled to death by cardiac puncture. Plasma was obtained, and kidneys removed and snap-frozen for further analysis.

Measurement of physiological and biochemical variables Upon completion of the study, mice were individually placed in metabolism cages (Tecniplast, Buguggiate, Italy) for a period of $24 \mathrm{~h}$. A blood sample was taken, body weight measured, food and water intake monitored and urine collected. Glycated haemoglobin was measured in whole blood by high performance liquid chromatography (CLC330 GHb Analyser; Primus, Kansas City, MO, USA) according to the AMDCC protocol [33]. Systolic blood pressure $(\mathrm{mmHg})$ was measured using the computerised non-invasive tail-cuff method (PowerLab, Chart version 5.2.2; AD Instruments, Bella Vista, NSW, Australia) as previously described $[22,28]$.

Measurement of kidney function Albumin excretion rates were measured in $24 \mathrm{~h}$ urine collections by a mouse albumin ELISA set (E90-134; Bethyl Laboratories, Montgomery, TX, USA) according to manufacturer's instructions. Creatinine clearance, corrected for body weight, was calculated using urine and plasma aliquots, which were mixed with acetyl nitrile (sample 1:5) and centrifuged at $4^{\circ} \mathrm{C}$, and the supernatant fraction removed. The samples were then dried in a speedivac, resuspended in $10 \mathrm{mmol} / \mathrm{l}$ ammonium acetate, $\mathrm{pH} 3.2$, and injected into a $\mathrm{C}_{18}$ column (Millipore Waters Division, Marlborough, MA, USA). HPLC was used to detect creatinine at $235 \mathrm{~nm}$ using a detector (PDA; Hewlett Packard, Palo Alto, CA, USA).

Histological assessment of kidney injury Kidney sections $(2 \mu \mathrm{m})$ were stained with periodic acid-Schiff's to visualise and quantify glomerulosclerosis (glomerular sclerotic index). The degree of glomerulosclerosis, which is defined as thickening of the glomerular basement membrane and mesangial expansion, was evaluated by a semi-quantitative method as described previously [32]. Sections (20 glomeruli per kidney section) were graded in a blinded fashion at magnification 400× using Image Pro-Plus (Media Cybernetics, Bethesda, MD, USA).

Renal fractionation In total, $50 \mathrm{mg}$ of renal cortex was homogenised (Polytron PT-MR2100; Kinematica, Lucerne, Switzerland) in extraction buffer $(20 \mathrm{mmol} / 1$ HEPES buffer, pH 7.2, 1 mmol/1 EGTA, $210 \mathrm{mmol} / 1$ mannitol, $70 \mathrm{mmol} / 1$ sucrose) to isolate nuclear, cytosol, mitochondrial and membranous fractions as previously described [28, 34]. Total protein for all fractions was determined by the bicinchoninic acid method (Pierce, Rockford, IL, USA) according to the manufacturer's protocol.

Renal superoxide production Fresh kidney cortex pieces $(1 \mathrm{~mm}$ in size) were placed in oxygen-saturated Krebs buffer (containing $118 \mathrm{mmol} / \mathrm{l} \mathrm{NaCl}, 4.7 \mathrm{mmol} / \mathrm{l} \mathrm{KCl}$, $1.2 \mathrm{mmol} / 1 \mathrm{MgSO}_{4} \cdot 7 \mathrm{H}_{2} \mathrm{O}, 1.2 \mathrm{mmol} / 1 \mathrm{KH}_{2} \mathrm{PO}_{4}, 11 \mathrm{mmol} / \mathrm{l} \mathrm{D}-$ glucose, $0.03 \mathrm{mmol} / \mathrm{l}$ EDTA and $2.5 \mathrm{mmol} / 1 \mathrm{CaCl}_{2}, \mathrm{pH} 7.4$ ). The rate of cytosolic and mitochondrial superoxide anion production was determined by lucigenin, as previously described [18].

Membranous RAGE production RAGE was measured in duplicate in 1:200 diluted membrane extracts using a mouse-specific RAGE DuoSet sandwich ELISA (R\&D Systems, Minneapolis, MN, USA). The assay was performed according to the company's instructions and absorbance measured at $540 \mathrm{~nm}$ on a 1420 multi-channel plate reader (Victor 3V; Perkin Elmer, Glen Waverley, VIC, Australia).

Measurement of angiotensin II Angiotensin II was measured in mouse plasma and renal cytosolic samples acquired at completion of the study, using a quantitative competitive sandwich enzyme immunoassay kit (AssayMax Human Angiotensin II ELISA; Assaypro, St Charles, MO, USA) according to the manufacturer's instructions. This assay is described by the manufacturer as being suitable for quantification of angiotensin II in mouse and rat samples.

Production of AT1 and AT2 receptors A total of 35 or $20 \mu \mathrm{g}$ (for production of AT2 or AT1 receptors, respectively) of renal cortical membrane extracts was loaded onto $10 \%$ (wt/vol.) precise protein gels (Thermo Scientific, Rockford, IL, USA) and run in Tris-HEPES buffer at $120 \mathrm{~V}$ for $60 \mathrm{~min}$. The protein was transferred on to a polyvinylidene difluoride membrane (Millipore, Bedford, MA, USA) followed by blocking for $1 \mathrm{~h}$ using $5 \%$ (wt/vol.) milk solution in PBS with Tween 20 while under agitation. The polyvinylidene difluoride membranes were then hybridised overnight with their respective rabbit polyclonal IgG primary antibody prepared in 2.5\% (wt/vol.) milk (AT2 1:750 against peptide sequence CSQKP SDKHL DAIP, EZBiolab, Westfield, IL, USA; AT1 1:750, Santa Cruz Biotechnology, Santa Cruz, CA, 
USA). The membrane was washed in PBS with Tween 20 for $3 \times 10 \mathrm{~min}$ and the blot hybridised with $1: 1,000$ secondary antibody anti-rabbit $\operatorname{IgG}$ (heavy and light chain) (Alpha Diagnostic, San Antonio, TX, USA). Following further washes, the blots were developed by incubating the blot in luminol electrochemiluminescence substrate (Alpha Diagnostic). The expression image was captured and quantified using a gel imaging system (Alpha Innotech, San Leandro, CA, USA). The receptor band was normalised to total protein loading, which was quantified by imaging and analysing the total protein amount visible after Coomassie Brilliant Blue R-250 (EMD Chemicals, Gibbstown, NJ, USA) staining of the membranes. The primers and probes for real-time RTPCR are described in Electronic supplementary material (ESM) Table 1; a methodological description of the technique is provided in the ESM methods.

AGE studies in primary mesangial cells Our in vitro studies were conducted in primary rat mesangial cells. This homogenous population of cells has been phenotyped as Thy 1.1-positive, and negative for RECA-1 (endothelial cell marker) and P-vulgaris (epithelial cell marker) [35]; they have previously been shown to express cell surface RAGE [34]. In addition, the mesangial cell is the most prominent cell type found in the glomerulus and is known to not only assist in control of glomerular filtration, but may also be involved in the response to local injury, including cell proliferation and basement membrane remodelling. In our first experiments, primary rat mesangial cells were incubated for 7 days in the presence and absence of AGE-modified BSA or BSA $100 \mu \mathrm{g} / \mathrm{ml}$ in DMEM containing $25 \mathrm{mmol} / \mathrm{l}$ Dglucose or $25 \mathrm{mmol} / 1 \mathrm{~L}$-glucose. Since the AGE $N^{\varepsilon}$ (carboxymethyl)lysine is a modification to the parent amino acid lysine, albumin was used as the protein source of lysine available for modification by advanced glycation.

For RAGE overproduction, primary rat mesangial cells were infected with an adenoviral vector encoding for fulllength human RAGE or its empty vector control (AdGO) and cultured in high glucose (25 mmol/1 DMEM) for $24 \mathrm{~h}$ at $2.85 \times 10^{8}$ plaque-forming units as previously described [18]. On the second day cells were treated with $100 \mu \mathrm{g} / \mathrm{ml}$ of AGE-modified BSA or BSA and cultured for a further $48 \mathrm{~h}$, with some cells exposed to the antioxidants apocynin $(1 \mu \mathrm{mol} / \mathrm{l}), \mathrm{N}$-acetylcysteine $(\mathrm{NAC} ; 1 \mathrm{mmol} / \mathrm{l})$ or soluble RAGE $(1 \mu \mathrm{g} / \mathrm{ml})$ from day 2 to 3 [34]. On the third day after infection or the seventh day for mesangial cells exposed to AGE-modified BSA or BSA alone, cells were washed and collected by gentle scraping, centrifuged at $1,500 \mathrm{~g}$ and the resulting pellet resuspended in PBS containing FBS. Cells $\left(1 \times 10^{5}\right.$ per tube) were then transferred to FACS tubes to stain for cell surface expression of RAGE, AT1 and AT2 as previously described [34]. Briefly, cells were stained for $30 \mathrm{~min}$ with $10 \mu \mathrm{l}$ of RAGE (N-16), AT1 (N-10) or AT2 (H-143; Santa Cruz) at room temperature, washed and then sequentially stained for $30 \mathrm{~min}$ with 1:500 dilution of phycoerythrin-conjugated secondary antibody, donkey-antigoat (RAGE) or goat-anti-rabbit (AT1 and AT2; Southern Biotech, Birmingham, AL, USA) at room temperature in the dark. After washing and resuspension in PBSF, a minimum of 10,000 events were acquired and positive cells identified according to fluorescence intensity above relative fluorescence to the secondary antibody alone using histogram analysis. Data are presented as percentage of control (L-glucose in nonadenoviral studies or AdGO adenoviral vector). To quantify superoxide production, cultured cells were stained with $10 \mu \mathrm{mol} / 1$ dihydroethidium (Molecular Probes Invitrogen, Carlsbad, CA, USA; $30 \mathrm{~min}, 37^{\circ} \mathrm{C}$, in dark), washed with excess PBS without $\mathrm{Mg}^{2+}$ and $\mathrm{Ca}^{2+}$, and centrifuged at $1,500 \mathrm{~g}$ and resuspended in $100 \mu \mathrm{l}$ PBS. Analysis by flow cytometry as described above was then performed.

\section{Results}

Metabolic and physiological variables As expected, all diabetic groups had elevated plasma glucose and glycated
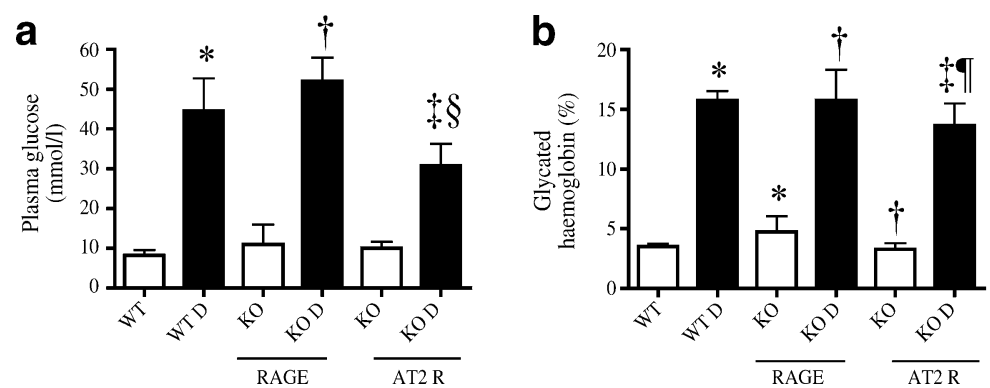

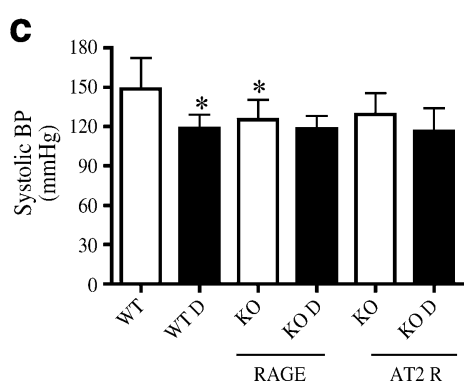

Fig. 1 Metabolic measures in diabetic and non-diabetic mice at week 24. a Plasma glucose and (b) glycated haemoglobin were measured in plasma and whole blood, respectively, collected from all mice at completion of the study. c Mean systolic blood pressure by tail cuff plethysmography. Data presented as mean $\pm \mathrm{SD}$ ( $n=10$ per group). ${ }^{*} p<$ 0.05 vs wild-type, ${ }^{\dagger} p<0.05$ vs Rage KO, ${ }^{\star} p<0.05$ vs At2 KO, ${ }^{\S} p<0.05$ vs Rage KO D, ${ }^{\top}<0.05$ vs wild-type D. AT2 R, AT2 receptor; D, diabetic; WT, wild-type 
Table 1 Physiological variables in diabetic and non-diabetic mice

\begin{tabular}{|c|c|c|c|c|c|c|c|}
\hline Group & BW (g) & Water (ml) & Food $(\mathrm{g})$ & Urine $(\mathrm{ml})$ & $\mathrm{KW} / \mathrm{BW}$ ratio $\left(\times 10^{-3}\right)$ & Left KW (g) & Right KW (g) \\
\hline Wild-type & $36.3 \pm 2.2$ & $3.5 \pm 0.9$ & $2.58 \pm 0.67$ & $1.75 \pm 0.29$ & $0.98 \pm 0.04$ & $0.17 \pm 0.01$ & $0.19 \pm 0.02$ \\
\hline Wild-type D & $25.3 \pm 1.9^{*}$ & $35.2 \pm 2.7^{*}$ & $8.14 \pm 0.41^{*}$ & $34.86 \pm 3.01 *$ & $1.80 \pm 0.22 *$ & $0.21 \pm 0.02$ & $0.25 \pm 0.04 *$ \\
\hline Rage KO & $38.6 \pm 3.3^{*}$ & $3.5 \pm 1.0$ & $2.19 \pm 0.64$ & $0.62 \pm 0.38^{*}$ & $1.11 \pm 0.08^{*}$ & $0.23 \pm 0.03^{*}$ & $0.24 \pm 0.04 *$ \\
\hline Rage KO D & $26.2 \pm 3.1 \dagger$ & $41.0 \pm 5.6^{\dagger \S}$ & $9.40 \pm 0.70^{\dagger \S}$ & $38.33 \pm 5.49 \dagger$ & $1.81 \pm 0.13^{\dagger}$ & $0.21 \pm 0.02 *$ & $0.23 \pm 0.02$ \\
\hline At2 $\mathrm{KO}$ & $38.0 \pm 3.9$ & $5.1 \pm 2.4$ & $2.13 \pm 0.70$ & $1.47 \pm 0.25$ & $1.20 \pm 0.19^{*}$ & $0.23 \pm 0.03 *$ & $0.22 \pm 0.03$ \\
\hline At2 KO D & $22.5 \pm 2.1 \$$ & $22.9 \pm 6.5^{ \pm \S}$ & $5.61 \pm 1.15^{\ddagger \S \Phi}$ & $24.50 \pm 7.09^{ \pm 8 \Phi}$ & $2.14 \pm 0.18^{\ddagger \S \rrbracket}$ & $0.26 \pm 0.04 * 8 \mp$ & $0.25 \pm 0.05^{*}$ \\
\hline
\end{tabular}

Data are presented as mean $\pm \mathrm{SD}$

${ }^{*} p<0.05$ vs wild-type; ${ }^{\dagger} p<0.05$ vs Rage KO; ${ }^{\dagger} p<0.05$ vs $A t 2 \mathrm{KO} ;{ }^{8} p<0.05$ vs wild-type D; ${ }^{\circledR} p<0.05$ vs Rage KO D

$\mathrm{BW}$, body weight; $\mathrm{D}$, diabetic; KW, kidney weight

haemoglobin concentrations (Fig. 1a, b). There was a modest decrease in plasma glucose in diabetic At2 KO compared with diabetic wild-type mice, which was also reflected in their lower glycated haemoglobin concentrations (Fig. 1b). Furthermore, systolic blood pressure was modestly decreased with diabetes in wild-type mice, but this was not affected by RAGE or AT2 deficiency (Fig. 1c). In general, diabetic mice consumed more water and food, had a greater urine output and a corresponding decrease in body weight (Table 1), although At2 $\mathrm{KO}$ mice consumed less water and had a lower urinary output. Kidney/body weight ratios were also greater in all diabetic mice (Table 1), and even further increased in the diabetic At2 $\mathrm{KO}$ mice. Diabetes increased the weight of right kidneys in wild-type mice (Table 1). Rage $\mathrm{KO}$ and At2 $\mathrm{KO}$ mice had greater kidney weights than wild-type mice and this was further exacerbated with diabetes in At2 $\mathrm{KO}$ mice (Table 1).

Renal function Increases in urinary AER were evident with diabetes in wild-type and At2 $\mathrm{KO}$ mouse groups (Fig. 2a, b). Importantly, an increase in AER was not seen in diabetic Rage $\mathrm{KO}$ mice compared with diabetic wild-type and At2 $\mathrm{KO}$ mice (Fig. 2a). While diabetes induced hyperfiltration in wild-type mice, this was not seen in diabetic Rage KO mice (Fig. 2c), while hyperfiltration was improved in At2 KO diabetic mice (Fig. 2d). Interestingly, both control Rage $\mathrm{KO}$ and At2 $\mathrm{KO}$ mice had lower creatinine clearance rates than wild-type mice. The deletion of RAGE ameliorated diabetes-induced elevations in glomerular sclerotic index; however, this was not seen with deletion of AT2, which increased glomerulosclerosis in control and diabetic At2 KO mice (Fig. 2e, f).

Renal RAGE production and superoxide production Rage gene production was elevated with diabetes in the wild-type mice, but was also increased in all At2 KO mice (Fig. 3a). As expected Rage gene expression was not detectable in Rage KO mice (Fig. 3a). Elevations in renal membranous Rage expression were also seen in wild-type and At2 $\mathrm{KO}$ mice with diabetes (Fig. 3b). AT2 control mice also had an increase in membranous RAGE compared with wild-type control mice. As anticipated, no membranous RAGE protein was detected in Rage KO mice (Fig. 3b). Excess renal cytosolic and mitochondrial superoxide generation was demonstrated in diabetic wild-type mice (Fig. 3c, d); this was attenuated by
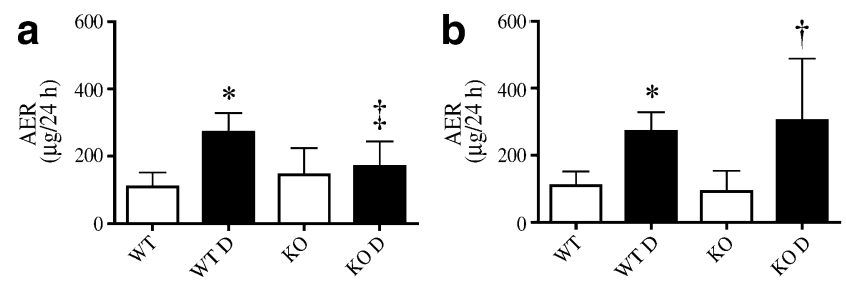

C

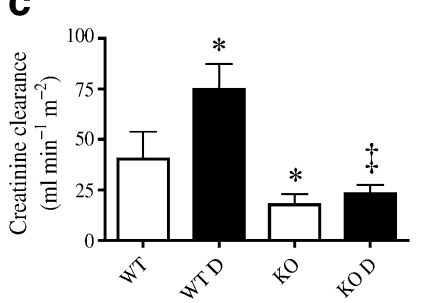

d
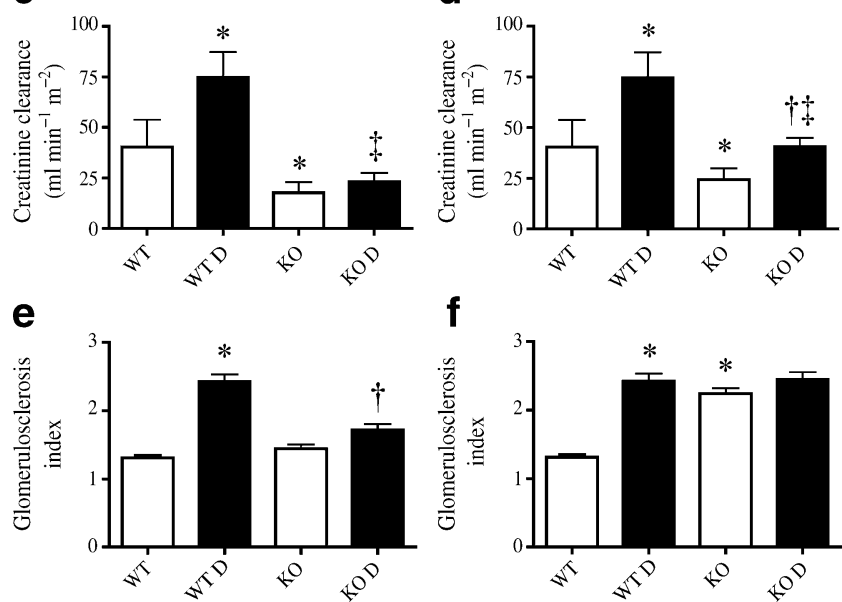

Fig. 2 Rage KO provides superior renoprotection to mice with diabetes than AT2 receptor deficiency. a AER over $24 \mathrm{~h}$ in Rage KO and (b) At $2 \mathrm{KO}$ mice. c Creatinine clearance in Rage $\mathrm{KO}$ and (d) At2 $\mathrm{KO}$ mice was assayed in plasma and urine samples collected from all mice with and without diabetes at study completion. AER and creatinine clearance were measured using ELISA and HPLC, respectively. As AER data were not normally distributed, they are expressed as geometric mean \pm tolerance factors. e Glomerular sclerotic index was quantified in Rage $\mathrm{KO}$ and (f) At2 $\mathrm{KO}$ mice using semiquantitative analysis of PAS stained renal sections. Values are mean $\pm \mathrm{SD}$ ( $n=10$ per group). ${ }^{*} p<0.05$ vs wild-type, ${ }^{\dagger} p<0.05$ vs $A t 2$ $\mathrm{KO},{ }^{\ddagger} p<0.05$ vs wild-type D. D, diabetic; WT, wild-type 


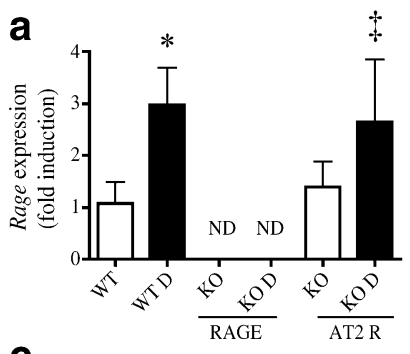

C

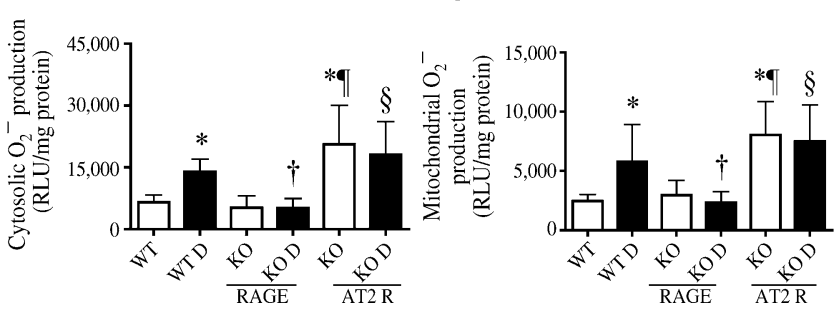

Fig. 3 Renal RAGE expression and superoxide production. At completion of the study renal tissue was collected to measure (a) Rage expression by RT-PCR, (b) renal membranous RAGE protein by ELISA, and (c) cytosolic and (d) mitochondrial superoxide production by lucigenin substrate enhanced chemiluminescence. Data presented as mean $\pm \mathrm{SD}$ ( $n=10$ per group). ${ }^{*} p<0.05$ vs wild-type (WT), ${ }^{\dagger} p<0.05$ vs wild-type D, ${ }^{\star} p<0.05$ vs At2 KO, ${ }^{\S} p<0.05$ vs Rage KO D, ${ }^{\natural} p<0.05$ vs Rage KO. AT2 R, AT2 receptor; D, diabetic; ND, not detected

Rage deletion. By contrast, At2 $\mathrm{KO}$ mice exhibited significantly higher renal superoxide production relative to the wildtype groups (Fig. 3c, d), which remained unaffected by diabetes.

Expression of RAS components The results for gene expression of RAS components are shown in Table 2, and the results are described in the ESM Results. Renal At2 gene expression was significantly increased with diabetes in wild-type mice, which was not seen in diabetic Rage $\mathrm{KO}$ mice. As expected, At2 gene expression was not detected in At2 $\mathrm{KO}$ mice (Fig. 4a). Renal cortical membranous produc- tion of AT2 receptor protein was also modestly elevated in diabetic wild-type mice. Interestingly, this was further increased by about fourfold in diabetic Rage KO mice (Fig. 4c). AT2 receptor protein production was not detected in At2 KO mice.

In vitro modulation of angiotensin II receptors by RAGE Based on our in vivo findings demonstrating potential interactions between RAGE and various components of the RAS, and in particular the likelihood that RAGE influences production of the AT2 receptor, we performed a series of in vitro studies on mesangial cells. AGEmodified BSA treatment of mesangial cells under highglucose conditions increased cell surface expression of RAGE (Fig. 5a) and resulted in excess reactive oxygen species (ROS) production as measured by dihydroethidium (Fig. 5d). In addition, while cell surface AT1 receptor expression tended to be elevated, there was a concomitant decline in cell surface AT2 receptor expression with AGEmodified BSA treatment (Fig. 5b, c). Overexpression of RAGE by adenovirus in primary mesangial cells induced upregulation of RAGE on the cell surface (Fig. 5e). Exposure of cells overexpressing RAGE to AGEmodified BSA treatment further enhanced cell surface expression of RAGE (Fig. 5e) and ROS production (Fig. 5h), which was prevented by concomitant incubation with the antioxidants NAC and apocynin, and by soluble RAGE. The AT1 receptor was elevated by RAGE overexpression, but no significant effects were seen with concomitant AGE exposure or with antioxidant therapy and soluble RAGE (Fig. 5f) in the context of AGE exposure. However, RAGE overexpression did decrease cell surface AT2 receptor expression in primary mesangial cells treated with AGE-modified BSA, which was abrogated with the antioxidants apocynin and NAC, and with soluble RAGE (Fig. 5g).

Table 2 Renal gene and circulating expression of RAS components and AGE receptors

\begin{tabular}{|c|c|c|c|c|c|c|c|c|}
\hline Group & At1a (gene) & $\begin{array}{l}\text { AT1 receptor } \\
\text { (protein) }\end{array}$ & $\begin{array}{l}\text { Ddost } \\
\text { (gene) }\end{array}$ & $\begin{array}{l}\text { AGE-R3 } \\
\text { (gene) }\end{array}$ & $\begin{array}{l}\text { Renin } \\
\text { (gene) }\end{array}$ & $\begin{array}{l}\text { Angiotensinogen } \\
\text { (gene) }\end{array}$ & $\begin{array}{l}\text { Plasma AngII } \\
\text { (protein) }^{\mathrm{a}}\end{array}$ & $\begin{array}{l}\text { Renal cytosolic } \\
\text { AngII (protein) }\end{array}$ \\
\hline Wild-type & $1.47 \pm 1.04$ & $1.00 \pm 0.00$ & $0.97 \pm 0.18$ & $1.26 \pm 0.91$ & $1.02 \pm 0.23$ & $1.04 \pm 0.12$ & $791.7 \pm 71.9$ & $0.04 \pm 0.06$ \\
\hline Wild-type D & $1.22 \pm 0.67$ & $0.83 \pm 0.30$ & $1.14 \pm 0.17$ & $1.47 \pm 0.72$ & $2.24 \pm 2.23$ & $1.34 \pm 0.42 *$ & $833.6 \pm 128.0$ & $0.02 \pm 0.04$ \\
\hline Rage $\mathrm{KO}$ & $3.12 \pm 1.65^{*}$ & $0.41 \pm 0.12 *$ & $0.53 \pm 0.09 *$ & $0.72 \pm 0.20$ & $0.93 \pm 0.26$ & $1.24 \pm 0.28$ & $809.9 \pm 125.3$ & $0.07 \pm 0.06$ \\
\hline Rage KO D & $2.17 \pm 1.59$ & $0.77 \pm 0.16^{\ddagger}$ & $0.67 \pm 0.05^{\dagger \dagger}$ & $1.13 \pm 0.38^{\ddagger}$ & $1.25 \pm 0.44^{\ddagger}$ & $2.07 \pm 0.95^{\star}$ & $753.9 \pm 56.3$ & $0.09 \pm 0.06^{\dagger}$ \\
\hline At2 $\mathrm{KO}$ & $5.07 \pm 1.93 * \star$ & $0.25 \pm 0.11 *$ & $0.70 \pm 0.08^{*}$ & $0.95 \pm 0.41$ & $0.71 \pm 0.23 *$ & $0.70 \pm 0.12 *$ & $251.6 \pm 94.2 * \hbar$ & $0.61 \pm 0.26^{* *}$ \\
\hline At2 KO D & $4.13 \pm 1.38^{\dagger}$ & $0.40 \pm 0.32$ & $0.68 \pm 0.15^{\dagger}$ & $2.16 \pm 0.75^{\S \uparrow}$ & $0.50 \pm 0.24^{\dagger}$ & $1.69 \pm 0.29^{\oplus}$ & $70.8 \pm 48.6^{\dagger \S \uparrow}$ & $0.61 \pm 0.35^{\dagger \S}$ \\
\hline
\end{tabular}

Data presented as mean $\pm \mathrm{SD}$; gene expression and protein levels were determined as described ("Methods")

${ }^{\mathrm{a}} \mathrm{In} \mathrm{pg} / \mathrm{ml}$, circulating levels or levels within renal cytosol respectively

${ }^{*} p<0.05$ vs wild-type; ${ }^{\dagger} p<0.05$ vs wild-type $\mathrm{D} ;{ }^{*} p<0.05$ vs Rage KO; ${ }^{\circledR} p<0.05$ vs Rage KO D; ${ }^{7} p<0.05$ vs At2 KO

AngII, angiotensin II; D, diabetic 

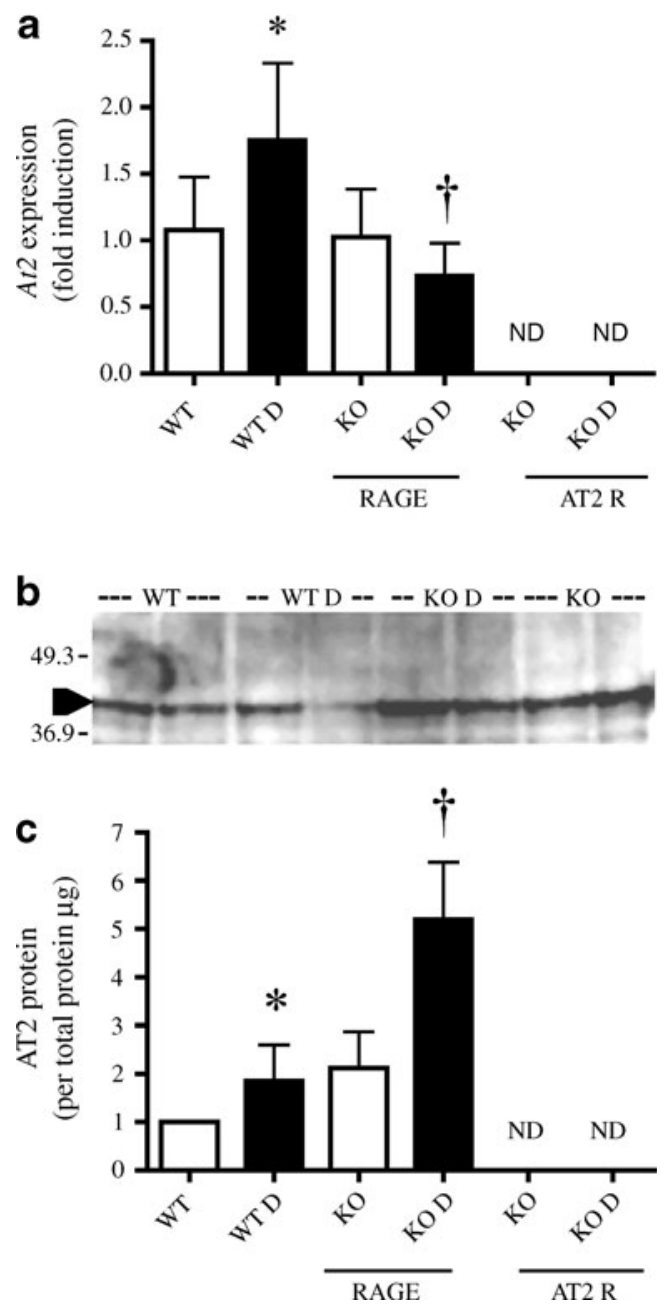

Fig. 4 Modulation of the AT2 receptor by RAGE. Renal AT2 expression was quantitated at the gene and protein level in tissue collected at completion of the study ( $n=10$ per group). a At2 expression in renal cortex by RT-PCR. b Representative western blot of AT2 in renal membranes from wild-type (WT) and Rage KO control and diabetic (D) mice. Arrowhead, AT2 band. c Protein production of AT2 receptor was measured on membranous fraction of renal cortex by western immunoblotting and corrected for total protein. Data $(\mathbf{a}, \mathbf{c})$ presented as mean $\pm \mathrm{SD}$. ${ }^{*} p<0.05$ vs wild-type, ${ }^{\dagger} p<0.05$ vs wild-type D. ND, not detected

\section{Discussion}

This group of studies investigated the relationship between RAGE and the AT2 receptor in the development of diabetic renal disease. We first identified that a deficiency in the RAGE receptor [18, 19], but not the AT2 receptor prevented various diabetes-related renal changes, including albuminuria and glomerular structural abnormalities (glomerulosclerosis), as seen in diabetic wild-type mice, in the absence of any effects on glycaemic control. We also observed an increase in production of the AT2 receptor and a decline in diabetes-associated renal mitochondrial and cytosolic superoxide production in diabetic Rage $\mathrm{KO}$ mice, changes that were not seen in diabetic At2 $\mathrm{KO}$ mice. Consistent with these in vivo findings, RAGE adenoviral overexpression in primary mesangial cells, as well as exposure to the well-described RAGE ligand, AGEmodified BSA, which also elevated cell surface RAGE expression, induced a decrease in cell surface expression of the AT2 receptor, in the context of excess cellular superoxide production. These findings thus suggest that RAGE plays a pivotal role in modulating renal AT2 receptor expression, particularly in the context of hyperglycaemia, as seen in diabetes (Fig. 6).

Although studied for the first time in the context of diabetes within the present study, the role of the AT2 receptor as a protective receptor has been suggested previously in other models of chronic kidney disease in At $2 \mathrm{KO}$ mice [36]. In addition, the wild-type C57BL/6J strain used in the present study is more susceptible to renal injury in diabetes than previously reported [37], a fact attributed to its decreased expression of nicotinamide nucleotide transhydrogenase due to mutation of the gene encoding this [38]. Indeed, this particular mouse strain develops a fourfold increase in albuminuria in response to diabetes (diabetic mice AER $253 \pm 101 \mu \mathrm{g} / 24 \mathrm{~h}$ vs control mice $55 \pm 35 \mu \mathrm{g} / 24 \mathrm{~h} ; n=200)$ and exhibits hyperfiltration and structural defects, albeit not very advanced. Therefore the wild-type C57BL/6J strain is useful in the study of early diabetic nephropathy and it is likely that these lesions develop solely due to hyperglycaemia. In addition, interpretation of results from this strain is not complicated by genetic modifications; we can therefore be confident that the changes observed following modification of one gene (such as in the Rage KO or At2 mice) resulted from that particular genetic manipulation.

Interestingly, no elevation in At2 expression in diabetic Rage KO mice was seen. Here it is possible that the discrepancy between the gene and protein levels of AT2 is a direct result of a compensatory negative feedback loop due to the high production of the AT2 receptor protein seen in Rage KO mice. Moreover, our findings in the present study suggest that once kidney disease is established, the presence of angiotensin II may, in fact, be protective, if its concentration remains below that required to modulate increases in AT1 receptor expression. The present study also showed that mesangial cells overexpressing RAGE had increased expression of the AT1a receptor in the context of a significant decline in AT2 cell surface expression and enhanced superoxide generation. Interestingly, blockade of ROS production by the antioxidants apocynin and NAC and by soluble RAGE restored cell surface AT2 expression, while the AT1 receptor remained unaffected, suggesting RAGE-mediated loss of AT2 is the major pathway for promoting superoxide generation in this model. This was also the case in our in vivo studies, where diabetes-induced 


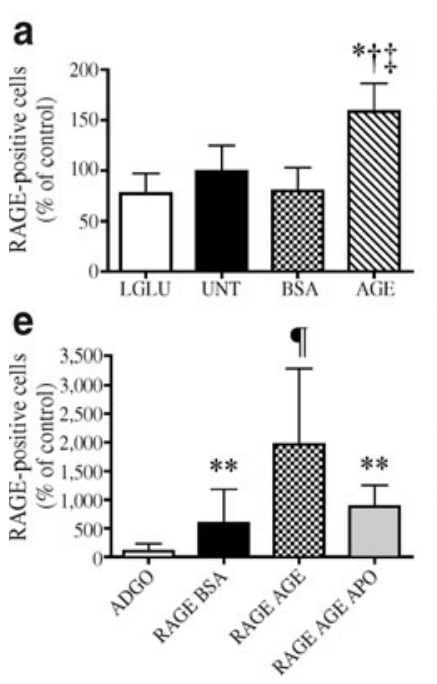

b
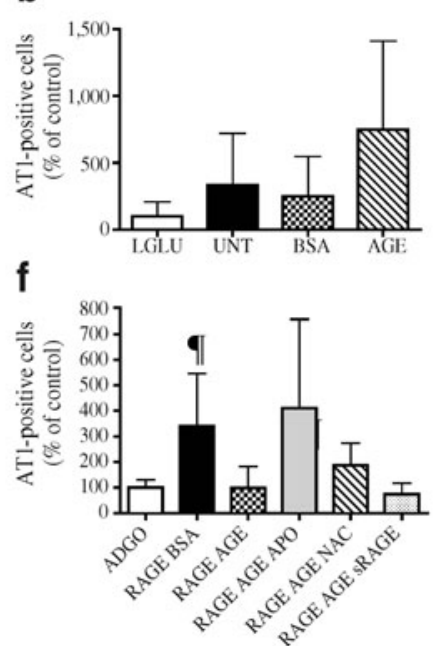

Fig. 5 AGE-RAGE interactions modulate AT2 receptor expression in primary mesangial cells. a-d Primary mesangial cells were treated with $100 \mu \mathrm{g} / \mathrm{ml}$ AGE-modified BSA. Data are representative of duplicate experiments ( $n=3-4$ per group/experiment). a Cell surface RAGE, (b) AT1 and (c) AT2 receptor expression by flow cytometry. d Intracellular ROS production was measured by dihydroethidium and flow cytometry. $\mathbf{e}-\mathbf{h}$ Mesangial cells were infected with an adenovirus overexpressing human full-length RAGE and treated with/without $100 \mu \mathrm{g} / \mathrm{ml} \mathrm{BSA}$ or AGE-modified BSA. Cells were analysed by flow cytometry for cell surface expression of (e) RAGE, (f) AT1 and (g) AT2 receptor, in addition to (h) intracellular ROS production. Data presented as mean $\pm \mathrm{SD}$. LGLU, $25 \mathrm{mmol} / 1$ low glucose control;

ROS generation was attenuated in Rage $\mathrm{KO}$ mice when renal AT2 receptors were increased in the absence of effects on the AT1 receptor. Interestingly, inhibition of the AT2 receptor by PD123319 has been shown to be ineffective in preventing generation of ROS [39, 40], although this may be due to its lack of specificity for the AT2 receptor. However, AT2 is thought to be a counterbalance to the NADPH-mediated increases in ROS generation signalled via the AT1 receptor, although our current findings suggest

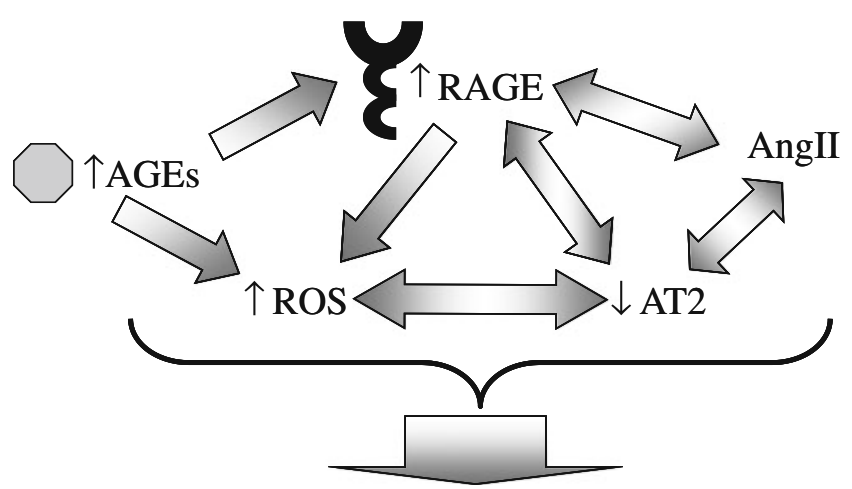

Diabetic renal disease

Fig. 6 Schematic diagram of the postulated interactions between pathogenic pathways in the development of diabetic renal disease. AngII, angiotensin II
C

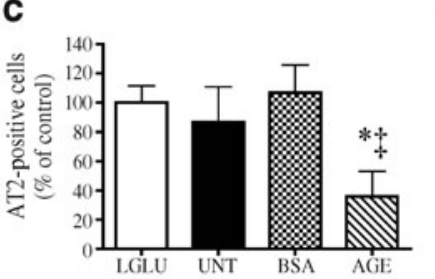

d
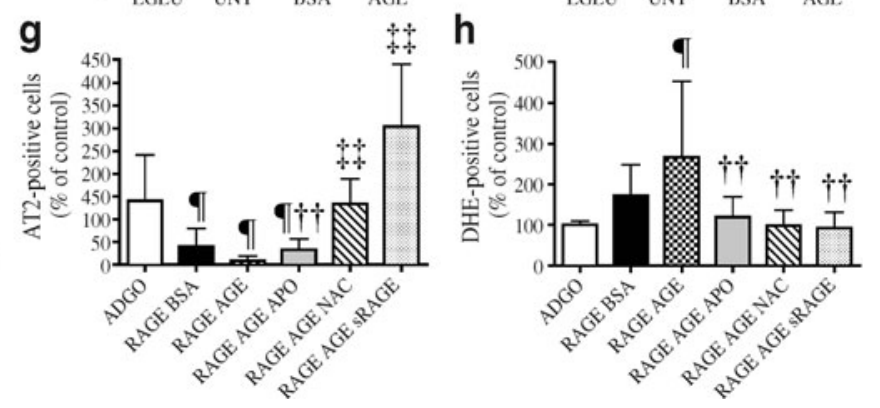

UNT, untreated cells cultured in $25 \mathrm{mmol} / 1 \mathrm{D}$-glucose; ADGO, adenoviral empty vector control; RAGE BSA, cells infected with RAGE adenovirus and treated with BSA; RAGE AGE, cells infected with RAGE adenovirus and treated with AGE-modified BSA; RAGE AGE APO/NAC/sRAGE, cells infected with RAGE and treated with AGE-modified BSA in the presence of $1 \mu \mathrm{mol} / 1$ apocynin, $1 \mathrm{mmol} / 1 \mathrm{NAC}$ or $1 \mu \mathrm{g} / \mathrm{ml}$ soluble RAGE, respectively. ${ }^{*} p<0.05$ vs LGLU, ${ }^{\dagger} p<0.05$ vs UNT, ${ }^{*} p<0.05$ vs BSA, ${ }^{\natural} p<0.05$ vs ADGO using unpaired Student's $t$ test, ${ }^{* *} p<0.05$ vs RAGE AGE using Mann-Whitney $U$ test, ${ }^{\dagger} p<0.05$ vs RAGE AGE using unpaired Student's $t$ test, ${ }^{\star} p<0.01$ vs RAGE AGE

an additional novel role for the AT2 receptor, namely in superoxide generation that is independent of AT1. Indeed, signalling via the AT2 receptor is thought to induce expression of bradykinin and nitric oxide, in addition to promoting growth inhibition, apoptosis and vasodilation in an attempt to counteract elevations in ROS [41, 42]. It is therefore not surprising that in this study a loss of AT2 expression was associated with increased renal superoxide production in diabetes and that, as shown here for the first time, this phenomenon appears to be mediated by RAGE.

AGE-mediated increases in RAGE expression and subsequent modulation of downstream pathways that lead to the development of diabetic nephropathy have been previously reported by our group and others $[18,34,43$, 44]. In our present study, increases in renal Rage mRNA and renal membrane RAGE protein levels were associated with increases in renal mitochondrial and cytosolic superoxide production in the presence of AGEs. This is consistent with previous studies from our group, demonstrating that increased ligation of AGEs to renal RAGE increases cytosolic ROS production, which subsequently drives mitochondrial ROS [18]. In our present study, moreover, we found that elevated levels of ROS production were seen with RAGE overexpression only in the presence of AGE-modified BSA. This further highlights the importance of RAGE as a central and key modulator of AGEs 
and RAS, which conjointly drive the development of diabetic nephropathy. In addition, the antioxidants apocynin and NAC prevented ROS production in mesangial cells, a finding consistent with our previous studies showing improvements in renal ROS production and renoprotection in diabetic rodents treated with apocynin [18, 34].

The absence of the AT2 receptor has been postulated to lead to vascular and renal hypersensitivity to angiotensin II, including sustained anti-natriuresis and hypertension [45]. In addition, increased levels of AT1 [46] decreased levels of bradykinin and cyclic GMP [41], which increased interstitial fluid levels of prostaglandins [47] and enhanced fibrosis within the kidney of At2 $\mathrm{KO}$ mice [5]. As increases in circulating angiotensin II were not seen in At2 $\mathrm{KO}$ mice in the present study, this may explain the absence of hypertension in these mice. This is in contrast to previous studies in At $2 \mathrm{KO}$ mice on a mixed background [5], a difference possibly explained by the pure C57BL/6J background used in the present study. Also of interest were the local elevations in renal angiotensin II levels. Furthermore, At2 $\mathrm{KO}$ mice did not adapt their water intake in response to diabetes to the same degree as seen in wildtype, and in particular in Rage KO mice. Indeed, previous studies have shown that At2 KO mice do not respond to angiotensin II-mediated signals to increase water intake [48, 49]. This was also reflected by the lower glomerular filtration rate and urinary output seen in diabetic At2 $\mathrm{KO}$ mice in the present study.

Hence, in the present study, we found that absence of RAGE appears to confer at least some of its renoprotective effects via modulation of the AT2 receptor in an animal model of diabetic renal disease (Fig. 6). Of particular interest was the finding that manipulation of RAGE resulted in direct effects on renal expression of the AT2 receptor in diabetes, probably via direct induction of ROS. Indeed, for the first time, we suggest that AT2 receptor deficiency is associated with enhanced renal disease in diabetes, while confirming that RAGE deficiency is protective and modulates the AT2 receptor. Taken together, these results suggest that RAGE antagonists, which are currently under clinical investigation for treatment of Alzheimer's disease and under consideration as therapy for diabetic complications, may have multiple effects in diabetic renal disease, not only via modulation of RAGE but also the AT2 receptor subtype.

\footnotetext{
Acknowledgements The authors would like to thank K. Gilbert for her expert care of the animals throughout the study, and S. Penfold, M. Arnstein and E. Grixti for their technical expertise. This work was completed with support from the Juvenile Diabetes Research Foundation (JDRF) and the National Health and Medical Research Council of Australia (NHMRC). J. M. Forbes is a JDRF Career Development Fellow. M. E. Cooper is an Australia Fellow of the NHMRC and a JDRF Scholar. A. Koitka is supported by an Association de Langue Française
}

pour l'Etude du Diabète et des Maladies Métaboliques (ALFEDIAM) fellowship. M. C. Thomas and J. M Forbes are supported by Kidney Health Australia (Bootle Award).

Duality of interest The authors declare that there is no duality of interest associated with this manuscript.

\section{References}

1. Mukoyama M, Nakajima M, Horiuchi M, Sasamura H, Pratt RE, Dzau VJ (1993) Expression cloning of type 2 angiotensin II receptor reveals a unique class of seven-transmembrane receptors. J Biol Chem 268:24539-24542

2. Murphy TJ, Alexander RW, Griendling KK, Runge MS, Bernstein KE (1991) Isolation of a cDNA encoding the vascular type-1 angiotensin II receptor. Nature 351:233-236

3. Ribeiro-Oliveira A Jr, Nogueira AI, Pereira RM, Boas WW, Dos Santos RA, Simoes e Silva AC (2008) The renin-angiotensin system and diabetes: an update. Vasc Health Risk Manag 4:787-803

4. Morrissey JJ, Klahr S (1999) Effect of AT2 receptor blockade on the pathogenesis of renal fibrosis. Am J Physiol 276:F39-F45

5. Ma J, Nishimura H, Fogo A, Kon V, Inagami T, Ichikawa I (1998) Accelerated fibrosis and collagen deposition develop in the renal interstitium of angiotensin type 2 receptor null mutant mice during ureteral obstruction. Kidney Int 53:937-944

6. Arima S, Endo Y, Yaoita H et al (1997) Possible role of P-450 metabolite of arachidonic acid in vasodilator mechanism of angiotensin II type 2 receptor in the isolated microperfused rabbit afferent arteriole. J Clin Invest 100:2816-2823

7. van Esch JH, Schuijt MP, Sayed J, Choudhry Y, Walther T, Jan Danser AH (2006) AT2 receptor-mediated vasodilation in the mouse heart depends on AT1A receptor activation. Br J Pharmacol 148:452-458

8. Miyazaki M, Takai S (2006) Tissue angiotensin II generating system by angiotensin-converting enzyme and chymase. J Pharmacol Sci 100:391-397

9. Wolf G (2004) New insights into the pathophysiology of diabetic nephropathy: from haemodynamics to molecular pathology. Eur J Clin Invest 34:785-796

10. UK Prospective Diabetes Study group (1998) Tight blood pressure control and risk of macrovascular and microvascular complications in type 2 diabetes: UKPDS 38. UK Prospective Diabetes Study Group. BMJ 317:703-713

11. Lewis EJ, Hunsicker LG, Bain RP, Rohde RD (1993) The effect of angiotensin-converting-enzyme inhibition on diabetic nephropathy. The Collaborative Study Group. N Engl J Med 329:1456-1462

12. Brenner BM, Cooper ME, de Zeeuw D et al (2000) The losartan renal protection study - rationale, study design and baseline characteristics of RENAAL (Reduction of Endpoints in NIDDM with the Angiotensin II Antagonist Losartan). J Renin Angiotensin Aldosterone Syst 1:328-335

13. Brenner BM, Cooper ME, de Zeeuw D et al (2001) Effects of losartan on renal and cardiovascular outcomes in patients with type 2 diabetes and nephropathy. N Engl J Med 345:861-869

14. Mogensen CE, Neldam S, Tikkanen I et al (2000) Randomised controlled trial of dual blockade of renin-angiotensin system in patients with hypertension, microalbuminuria, and non-insulin dependent diabetes: the candesartan and lisinopril microalbuminuria (CALM) study. BMJ 321:1440-1444

15. Mauer M, Zinman B, Gardiner R et al (2009) Renal and retinal effects of enalapril and losartan in type 1 diabetes. N Engl J Med 361:40-51

16. Bilous R, Chaturvedi N, Sjolie AK et al (2009) Effect of candesartan on microalbuminuria and albumin excretion rate in diabetes: three randomized trials. Ann Intern Med 151:11-20 
17. Flyvbjerg A, Denner L, Schrijvers BF et al (2004) Long-term renal effects of a neutralizing RAGE antibody in obese type 2 diabetic mice. Diabetes 53:166-172

18. Coughlan MT, Thorburn DR, Penfold SA et al (2009) RAGEinduced cytosolic ROS promote mitochondrial superoxide generation in diabetes. J Am Soc Nephrol 20:742-752

19. Myint KM, Yamamoto Y, Doi T et al (2006) RAGE control of diabetic nephropathy in a mouse model: effects of RAGE gene disruption and administration of low-molecular weight heparin. Diabetes 55:2510-2522

20. Yamamoto Y, Kato I, Doi T et al (2001) Development and prevention of advanced diabetic nephropathy in RAGEoverexpressing mice. J Clin Invest 108:261-268

21. Inagi R, Yamamoto Y, Nangaku M et al (2006) A severe diabetic nephropathy model with early development of nodule-like lesions induced by megsin overexpression in RAGE/iNOS transgenic mice. Diabetes 55:356-366

22. Forbes JM, Thorpe SR, Thallas-Bonke V et al (2005) Modulation of soluble receptor for advanced glycation end products by angiotensin-converting enzyme-1 inhibition in diabetic nephropathy. J Am Soc Nephrol 16:2363-2372

23. Miyata T, van Ypersele de Strihou C, Ueda Y et al (2002) Angiotensin II receptor antagonists and angiotensin-converting enzyme inhibitors lower in vitro the formation of advanced glycation end products: biochemical mechanisms. J Am Soc Nephrol 13:2478-2487

24. Nakamura K, Yamagishi S, Nakamura Y et al (2005) Telmisartan inhibits expression of a receptor for advanced glycation end products (RAGE) in angiotensin-II-exposed endothelial cells and decreases serum levels of soluble RAGE in patients with essential hypertension. Microvasc Res 70:137-141

25. Forbes JM, Thomas MC, Thorpe SR, Alderson NL, Cooper ME (2004) The effects of valsartan on the accumulation of circulating and renal advanced glycation end products in experimental diabetes. Kidney Int Suppl:S105-S107

26. Thomas MC, Tikellis C, Burns WM et al (2005) Interactions between renin angiotensin system and advanced glycation in the kidney. J Am Soc Nephrol 16:2976-2984

27. Ruster C, Bondeva T, Franke S, Tanaka N, Yamamoto H, Wolf G (2009) Angiotensin II upregulates RAGE expression on podocytes: role of AT2 receptors. Am J Nephrol 29:538-550

28. Coughlan MT, Thallas-Bonke V, Pete J et al (2007) Combination therapy with the advanced glycation end product cross-link breaker, alagebrium, and angiotensin converting enzyme inhibitors in diabetes: synergy or redundancy? Endocrinology 148:886-895

29. Ichiki T, Labosky PA, Shiota C et al (1995) Effects on blood pressure and exploratory behaviour of mice lacking angiotensin II type-2 receptor. Nature 377:748-750

30. Bierhaus A, Haslbeck KM, Humpert PM et al (2004) Loss of pain perception in diabetes is dependent on a receptor of the immunoglobulin superfamily. J Clin Invest 114:1741-1751

31. Constien R, Forde A, Liliensiek B et al (2001) Characterization of a novel EGFP reporter mouse to monitor Cre recombination as demonstrated by a Tie2 Cre mouse line. Genesis 30:36-44

32. Forbes JM, Cooper ME, Thallas V et al (2002) Reduction of the accumulation of advanced glycation end products by ACE inhibition in experimental diabetic nephropathy. Diabetes 51:3274-3282
33. Dunn SR, Qi Z, Bottinger EP, Breyer MD, Sharma K (2004) Utility of endogenous creatinine clearance as a measure of renal function in mice. Kidney Int 65:1959-1967

34. Thallas-Bonke V, Thorpe SR, Coughlan MT et al (2008) Inhibition of NADPH oxidase prevents advanced glycation end product-mediated damage in diabetic nephropathy through a protein kinase C-alpha-dependent pathway. Diabetes 57:460-469

35. Fukami K, Ueda S, Yamagishi $\mathrm{S}$ et al (2004) AGEs activate mesangial TGF-beta-Smad signaling via an angiotensin II type I receptor interaction. Kidney Int 66:2137-2147

36. Benndorf RA, Krebs C, Hirsch-Hoffmann B et al (2009) Angiotensin II type 2 receptor deficiency aggravates renal injury and reduces survival in chronic kidney disease in mice. Kidney Int 75:1039-1049

37. Breyer MD, Bottinger E, Brosius FC 3rd et al (2005) Mouse models of diabetic nephropathy. J Am Soc Nephrol 16:27-45

38. Freeman HC, Hugill A, Dear NT, Ashcroft FM, Cox RD (2006) Deletion of nicotinamide nucleotide transhydrogenase: a new quantitive trait locus accounting for glucose intolerance in C57BL/6J mice. Diabetes 55:2153-2156

39. Ding G, Zhang A, Huang S et al (2007) ANG II induces c-Jun NH2-terminal kinase activation and proliferation of human mesangial cells via redox-sensitive transactivation of the EGFR. Am J Physiol Renal Physiol 293:F1889-F1897

40. Tsang SW, Ip SP, Leung PS (2004) Prophylactic and therapeutic treatments with AT 1 and AT 2 receptor antagonists and their effects on changes in the severity of pancreatitis. Int J Biochem Cell Biol 36:330-339

41. Siragy HM, Carey RM (1999) Protective role of the angiotensin AT2 receptor in a renal wrap hypertension model. Hypertension 33:1237-1242

42. Siragy HM, Carey RM (1997) The subtype 2 (AT2) angiotensin receptor mediates renal production of nitric oxide in conscious rats. J Clin Invest 100:264-269

43. Wautier MP, Chappey O, Corda S, Stern DM, Schmidt AM, Wautier JL (2001) Activation of NADPH oxidase by AGE links oxidant stress to altered gene expression via RAGE. Am J Physiol Endocrinol Metab 280:E685-E694

44. Forbes JM, Coughlan MT, Cooper ME (2008) Oxidative stress as a major culprit in kidney disease in diabetes. Diabetes 57:1446-1454

45. Siragy HM, Inagami T, Ichiki T, Carey RM (1999) Sustained hypersensitivity to angiotensin II and its mechanism in mice lacking the subtype-2 (AT2) angiotensin receptor. Proc Natl Acad Sci U S A 96:6506-6510

46. Saavedra JM, Hauser W, Ciuffo G et al (2001) Increased AT(1) receptor expression and mRNA in kidney glomeruli of AT(2) receptor gene-disrupted mice. Am J Physiol Renal Physiol 280:F71-F78

47. Siragy HM, Carey RM (1997) The subtype 2 angiotensin receptor regulates renal prostaglandin F2 alpha formation in conscious rats. Am J Physiol 273:R1103-R1107

48. Wang H, Gallinat S, Li HW, Sumners C, Raizada MK, Katovich MJ (2004) Elevated blood pressure in normotensive rats produced by 'knockdown' of the angiotensin type 2 receptor. Exp Physiol 89:313-322

49. Li Z, Iwai M, Wu L et al (2003) Role of AT2 receptor in the brain in regulation of blood pressure and water intake. Am J Physiol Heart Circ Physiol 284:H116-H121 